Correspondence: M.F. Raphael, Dept of Paediatric Hematology and Oncology, Wilhelmina Children's Hospital, University Medical Center Utrecht, Lundlaan 6, 3584 EA Utrecht, the Netherlands. E-mail: m.f.raphael-2@umcutrecht.nl

Statement of Interest: None declared.

\section{REFERENCES}

1 Peters SG, Afessa B. Acute lung injury after hematopoietic stem cell transplantation. Clin Chest Med 2005; 26: 561-569.

2 Afessa B, Peters SG. Chronic lung disease after hematopoietic stem cell transplantation. Clin Chest Med 2005; 26: 571-586.

3 Reddy P. Pathophysiology of acute graft-versus-host disease. Hematol Oncol 2003; 21: 149-161.
4 Pellegrino R, Viegi G, Brusasco V, et al. Interpretative strategies for lung function tests. Eur Respir J 2005; 26: 948-968.

5 Gassner FJ, Weiss L, Geisberger R, et al. Fludarabine modulates composition and function of the T cell pool in patients with chronic lymphocytic leukemia. Cancer Immuno Immunther 2011; 60: 75-85.

6 Versluys $\mathrm{AB}$, Rossen JW, van Ewijk B, et al. Strong association between respiratory viral infection early after hematopoietic stem cell transplantation and the development of life-threatening acute and chronic alloimmune syndromes. Biol Blood Marrow Transplant 2010; 16: 782-791.

7 Saini DJ, Weber S, Ramachandran D, et al. Alloimmunity-induced autoimmunity as a potential mechanism in the pathogenesis of chronic rejection of human lung allografts. J Heart Lung Transplant 2011; 30: 624-631.

\title{
Isolation of cells from the lower airways in infants with wheeze by sputum induction
}

\section{To the Editor:}

Preschool wheezing affects up to $50 \%$ of children [1, 2], of whom approximately half will have stopped experiencing wheezy episodes by the age of 6 yrs [2]. Results from large cohort studies [2, 3] raise several important questions. First, when facing a child with preschool wheeze, how can we predict the natural history and identify those children who are going to grow out of their asthma by mid-childhood and distinguish them from those who develop classical, adult-type asthma? Secondly, how can we identify those children who are likely to benefit from treatment with inhaled corticosteroids, leukotriene receptor antagonists or both, in the absence of reliable immunological criteria underpinning these decisions? Airway inflammation is a key feature of asthma and is detectable in preschool children [4]. Obtaining lower-airway samples from preschool children usually involves bronchoalveolar lavage sampling under general anaesthesia and is therefore reserved for children with problematic severe asthma or where the diagnosis is in doubt [4].

An alternative method of obtaining samples noninvasively from the lower airways is by sputum induction [5]. The use of induced sputum in infants has been limited [6-8] and inflammatory cell profiles have not been reported. MuSSAFFI et al. [6] performed the procedure in young children with cystic fibrosis and reported that the procedure was well tolerated, and there was a high success rate in nonexpectorating patients. Successful use of sputum induction in the diagnosis of tuberculosis was reported in 142 out of 149 infants with a median age of 9 months [7]. The aim of our pilot study was to investigate the feasibility of obtaining lower airway samples adequate for quantification of cell types from young infants with a history of wheezing, by sputum induction.

Infants aged 0-2 yrs requiring one or more hospital admissions with wheezing or wheezing episodes resulting in referral to a specialist paediatric respiratory clinic were recruited. Infants with other significant medical conditions were excluded. Written parental consent was obtained. The local research ethics committee (Leicestershire, Northamptonshire and Rutland REC 1, Nottingham, UK; reference number 06/Q2501/18) approved all aspects of this study.

Families attended our infant lung function laboratory once the child had been free from respiratory tract infection or wheeze for $\geqslant 2$ weeks. Infants were examined by a paediatrician (A. Whittaker) and, if they were well and baseline arterial oxygen saturations were $\geqslant 95 \%$ in room air, the infant was studied. They were allowed to fall asleep naturally; however, four very active children were given a mild sedative (chloral hydrate, $50 \mathrm{mg} \cdot \mathrm{kg}^{-1}$ body weight, by mouth). When settled, the infants were given inhaled salbutamol (200 $\mu$ g given via metered-dose inhaler and spacer) 10 min prior to sputum induction with $4 \%$ nebulised hypertonic saline, delivered through a high-flow nebuliser and facemask for $2 \mathrm{~min}$. A sputum sample was collected by suctioning via a soft, small-bore catheter inserted through the nasopharynx.

The sputum was processed within $2 \mathrm{~h}$ of collection at $4{ }^{\circ} \mathrm{C}$ as described previously [9]. Cytospins were prepared using $75 \mu \mathrm{L}$ cell suspension at $40 \times g(450 \mathrm{rpm})$ for 6 min using a Shandon III cytocentrifuge (Shandon Southern Instruments, Sewickley, PA, USA). Two air-dried slides were stained using the DiffQuik method (Dade Behring, Düdingen, Switzerland) for calculation of the leukocyte differential cell count. Initially, the percentage of squamous cells in the sample was estimated by counting 300 successive cells from a representative section of the slide. Following this, a differential leukocyte count was established by counting 300 nonsquamous cells. Cell counts were performed by an investigator (A. Tellebati) who was blinded to the clinical patient data. A detailed review was undertaken (E.A. Gaillard and J. Grigg) under different levels of magnification. The slides were also reviewed by a paediatric 

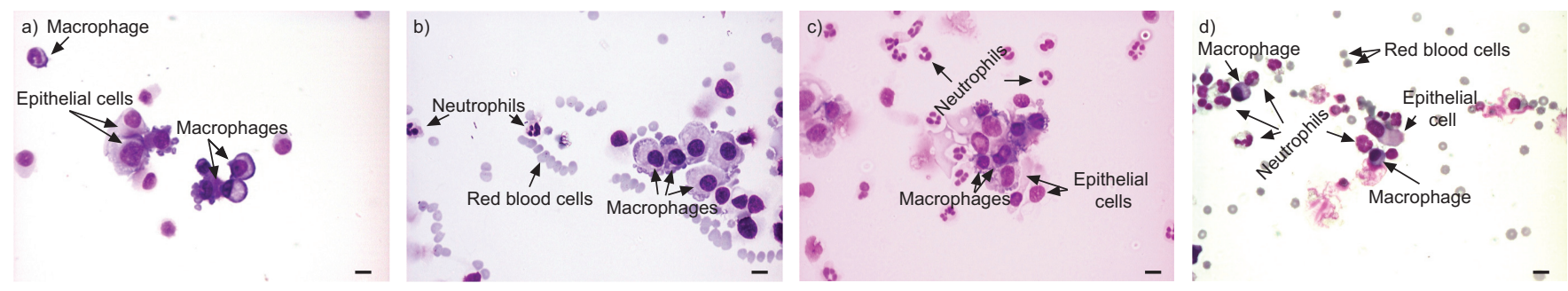

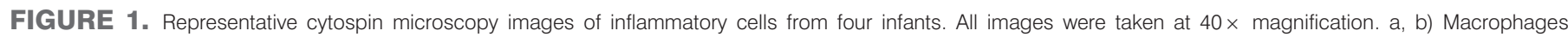

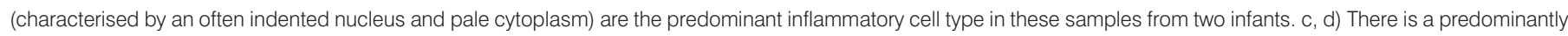

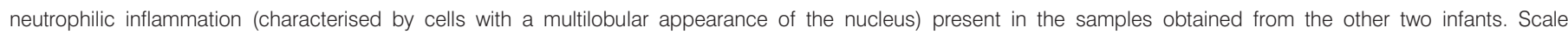
bars $=20 \mu \mathrm{m}$

haematologist (W. Abd-Elghany, University Hospitals Leicester, Leicester, UK).

Over the study period, 43 families were approached of which 22 initially agreed to participate. Six infants from the original 22 underwent sputum induction. Reasons for drop-out from the study were loss to contact $(n=8)$, withdrawal $(n=1)$, never being well enough to participate $(n=3)$ and being unwell on the day $(n=4)$. The median age of the children (five males and one female) in this study was 11.5 months (range 6-14 months). Three infants had eczema and a family history of atopy, and three were exposed to environmental tobacco smoke. Five infants were prescribed inhaled $\beta_{2}$-agonists and three, additionally, inhaled corticosteroids.

There were no adverse events and all the infants were allowed to go home immediately following the procedure. No significant differences in arterial oxygen saturation, median respiratory rate or median heart rate were observed before or after sputum induction (data not shown). Sputum was obtained from all six subjects with leukocytes isolated from four infants. The median percentage epithelial cells was 32\% (range 8-54\%). Lymphocytes were seen in one sample only ( $1 \%$ of total leukocytes) and no eosinophils were present in any of the samples. The median percentage neutrophils was $56 \%$ (range $0-82 \%$ ) and the median percentage macrophages was $44 \%$ (range 18-99\%). Figure 1 shows representative sections of cytospins obtained from four infants.

This is, to our knowledge, the first report of sputum induction in infants with wheeze. Our pilot study shows that the technique is feasible, safe and well tolerated. Neutrophil granulocytes and macrophages were the predominant inflammatory cell types isolated. Eosinophils were not found in any of the sputum samples, in keeping with previous studies in young children with severe wheeze [4]. The presence of macrophages in our samples suggests that lower-airway secretions were obtained using our induced sputum technique. The neutrophils may have originated in the upper or lower respiratory tract, although all the children were clinically free from respiratory infections at the time of the study.

The inflammatory phenotype present in two out of four infants was neutrophilic ( $>60 \%$ neutrophils) whereas in the other two infants, macrophages predominated. It is of note that the infants with neutrophilic inflammation also had eczema and a family history of atopy, whereas the infants with fewer neutrophils and predominantly macrophages had no eczema or family history of atopy. Clearly, the numbers in this pilot study are too small to draw any firm conclusions, and these findings will have to be verified in a larger study that includes healthy controls because the normal neutrophil differential cell count varies considerably in the healthy airway of older children and adults.

The pathophysiological and immunological mechanisms that contribute to the development of early infant wheezing have not been established, and this limits the understanding of the natural history of preschool wheezing [10]. The technique of sputum induction to obtain respiratory samples from the lower airways is attractive as a relatively noninvasive means to assess airway inflammation in infants. There is an urgent need to understand the different immunopathologies that underpin wheezing phenotypes in the paediatric population at an earlier stage, which could be of prognostic value to individual families as well as facilitating research into the early origins of asthma. The study highlights the difficulties of recruiting and studying infants with wheeze and any future studies must recruit substantially more subjects than the eventual number to be studied.

This pilot study shows that the technique of induced sputum in infants as a means of obtaining inflammatory cells from the lower airways, though difficult, is feasible and may also have a potential use in the detection and monitoring of airway inflammation in infants and young children with cystic fibrosis.

\section{Erol A. Gaillard*, Jonathan Grigg", Ananth Tellabati*,} Teresa McNally*, Amy Whittaker ${ }^{*}$ and Caroline S. Beardsmore* *Dept of Infection, Immunity and Inflammation, and Institute for Lung Health, University of Leicester, Leicester, and "Barts and The London School of Medicine and Dentistry, London, UK. "Diagnostic and Assessment Services, The St George Hospital, Kogarah, NSW, Australia.

Correspondence: E.A. Gaillard, Dept of Infection, Immunity and Inflammation, University of Leicester, PO Box 65, Robert Kilpatrick Clinical Sciences Building, Leicester Royal Infirmary, Leicester, LE2 7LX, UK. E-mail: eag15@le.ac.uk

Support Statement: The study was supported by Asthma UK.

Statement of Interest: A statement of interest for J. Grigg can be found at www.erj.ersjournals.com/site/misc/statements. xhtml 
Acknowledgements: The authors thank W. Abd-Elghany (University Hospitals Leicester, Leicester, UK) for reviewing the cytospin slides.

\section{REFERENCES}

1 Kuehni CE, Davis A, Brooke AM, et al. Are all wheezing disorders in very young (preschool) children increasing in prevalence? Lancet 2001; 357: 1821-1825.

2 Martinez FD, Wright AL, Taussig LM, et al. Asthma and wheezing in the first six years of life. The Group Health Medical Associates. N Engl J Med 1995; 332: 133-138.

3 Henderson J, Granell R, Heron J, et al. Associations of wheezing phenotypes in the first 6 years of life with atopy, lung function and airway responsiveness in mid-childhood. Thorax 2008; 63: 974-980.

4 Saglani S, Payne DN, Zhu J, et al. Early detection of airway wall remodeling and eosinophilic inflammation in preschool wheezers. Am J Respir Crit Care Med 2007; 176: 858-864.
5 Lex C, Payne DN, Zacharasiewicz A, et al. Sputum induction in children with difficult asthma: safety, feasibility, and inflammatory cell pattern. Pediatr Pulmonol 2005; 39: 318-324.

6 Mussaffi H, Fireman EM, Mei-Zahav M, et al. Induced sputum in the very young: a new key to infection and inflammation. Chest 2008; 133: 176-182.

7 Zar HJ, Tannenbaum E, Apolles P, et al. Sputum induction for the diagnosis of pulmonary tuberculosis in infants and young children in an urban setting in South Africa. Arch Dis Child 2000; 82: 305-308.

8 Yamada Y, Yoshihara S, Arisaka O. Creola bodies in wheezing infants predict the development of asthma. Pediatr Allergy Immunol 2004; 15: 159-162.

9 Pavord ID, Pizzichini MM, Pizzichini E, et al. The use of induced sputum to investigate airway inflammation. Thorax 1997; 52: 498-501.

10 Brand PL, Baraldi E, Bisgaard H, et al. Definition, assessment and treatment of wheezing disorders in preschool children: an evidence-based approach. Eur Respir J 2008; 32: 1096-1110.

DOI: $10.1183 / 09031936.00160412$ 